\title{
Language-specific and universal influences in children's syntactic packaging of Manner and Path: A comparison of English, Japanese, and Turkish
}

\author{
Shanley Allen ${ }^{a, b, *}$, Aslı Özyürek ${ }^{c, d, e}$, Sotaro Kita ${ }^{f}$, \\ Amanda Brown ${ }^{\text {b,d }}$, Reyhan Furman ${ }^{\mathrm{g}}$, \\ Tomoko Ishizuka ${ }^{\mathrm{h}}$, Mihoko Fujii ${ }^{\mathrm{i}}$ \\ ${ }^{a}$ School of Education, Boston University, 2 Sherborn Street, Boston, MA 02215, USA \\ ${ }^{\mathrm{b}}$ Graduate Program in Applied Linguistics, Boston University, 96 Cummington Street, \\ Boston, MA 02215, USA \\ ${ }^{\mathrm{c}}$ F.C. Donders Center for Cognitive Neuroimaging, Radboud University, \\ Adelbertusplein 1, 6525 EK Nijmegen, The Netherlands \\ d Max Planck Institute for Psycholinguistics, Wundtlaan 1, 6525 XD Nijmegen, The Netherlands \\ ${ }^{\mathrm{e}}$ Department of Psychology, Koç University, Rumeli Feneri Yolu, 34450 Sariyer, Istanbul, Turkey \\ ${ }^{\mathrm{f}}$ Department of Experimental Psychology, University of Bristol, 8 Woodland Road, BS8 1TN, Bristol, UK \\ ${ }^{\mathrm{g}}$ Program in Linguistics, Department of Western Languages and Literatures, \\ Bogazici University, 34342 Bebek, Istanbul, Turkey \\ ${ }^{\mathrm{h}}$ Department of Linguistics, University of California Los Angeles, 3125 Campbell Hall, \\ Los Angeles, CA 90095-1543, USA \\ i Japan Society for the Promotion of Science, Tokyo, Japan
}

Received 8 August 2005; revised 2 December 2005; accepted 2 December 2005

\begin{abstract}
\footnotetext{
This manuscript was accepted under the editorship of Jacques Mehler

* Corresponding author.

E-mail address: shanley@bu.edu (S. Allen).
}

Different languages map semantic elements of spatial relations onto different lexical and syntactic units. These crosslinguistic differences raise important questions for language devel- 
opment in terms of how this variation is learned by children. We investigated how Turkish-, English-, and Japanese-speaking children (mean age 3;8) package the semantic elements of Manner and Path onto syntactic units when both the Manner and the Path of the moving Figure occur simultaneously and are salient in the event depicted. Both universal and language-specific patterns were evident in our data. Children used the semantic-syntactic mappings preferred by adult speakers of their own languages, and even expressed subtle syntactic differences that encode different relations between Manner and Path in the same way as their adult counterparts (i.e., Manner causing vs. incidental to Path). However, not all types of semantics-syntax mappings were easy for children to learn (e.g., expressing Manner and Path elements in two verbal clauses). In such cases, Turkish- and Japanesespeaking children frequently used syntactic patterns that were not typical in the target language but were similar to patterns used by English-speaking children, suggesting some universal influence. Thus, both language-specific and universal tendencies guide the development of complex spatial expressions.

(C) 2006 Elsevier B.V. All rights reserved.

Keywords: Spatial language; Motion events; Development of syntax; Crosslinguistic comparison

\section{Introduction}

Speaking requires linearization of multidimensional information into sequential speech segments. This process is especially evident in talking about three-dimensional spatial information (Levelt, 1984). Different languages have different ways of distributing features of the same spatial information into linguistic units. Recent research has shown significant crosslinguistic differences in the way semantic elements of space are mapped onto lexical and syntactic structures (Choi \& Bowerman, 1991; Slobin, 1987; Talmy, 1985). For example, lexicalization of the semantic elements differs across language types. Speakers of satellite-framed languages such as English tend to conflate Motion with Manner in the main verb (e.g., roll in (1)) and express the Path in a non-verbal element, namely a "satellite" (e.g., down). In contrast, speakers of verb-framed languages such as Turkish and Japanese tend to conflate Motion with Path in the main verb (e.g., in- in (2)) and express Manner in a subordinate verb (e.g., yuvarlan-), an adverbial, or not at all. Further, Manner and Path occurring simultaneously in a motion event can be encoded in speech within one or two clauses depending on the typology of the language (Talmy, 1985). Speakers of satellite-framed languages typically use one clause to encode Manner and Path, as shown in (1). However, speakers of verb-framed languages typically use two separate clauses, mostly in a matrix-subordinate construction, as shown in the Turkish sentence in (2).

(1) The ball rolled down the hill

(2) Top yuvarlan-arak tepe-den aşăgl in-di. ball roll-Connective hill-Ablative downness descend-Past

'The ball descended the hill while rolling'. 
Such crosslinguistic differences raise a number of important questions for language development, including how this variation is learned by children speaking different languages (e.g., Berman \& Slobin, 1994; Bowerman \& Choi, 2001; Choi \& Bowerman, 1991; Johnston \& Slobin, 1979; Slobin, 1982). That is, to what extent do children learning different languages use similar mappings of semantic elements onto lexical and syntactic structures, and to what extent do they follow the language-specific patterns of their native languages? Further, when a given language offers other options than the typologically preferred construction, are children sensitive to the contexts in which each is preferred by adults?

Many studies to date have explored children's lexicalization of semantic elements of motion events and their expression in discourse. They have specifically asked which motion element is expressed within the main verb, and which is expressed in a satellite or subordinate verb, or omitted from speech altogether (e.g., Choi \& Bowerman, 1991; Oh, 2003; Özçalişkan \& Slobin, 1999; Papafragou, Massey, \& Gleitman, 2002). These studies have all found that children ranging from 19 months to 12 years old follow language-specific patterns regardless of their age.

However, virtually no studies (with the exception of $\mathrm{Oh}, 2003$ ) have looked at the mapping of semantic elements onto syntactic structures to determine how children learn to package Manner and Path together in their motion event speech. In addition, the data for previous studies has often been elicited using stimuli in which Manner of motion is optional rather than salient, so children often do not express both Manner and Path in their speech. Finally, no studies to our knowledge have looked at children's sensitivity to use of different types of syntactic packaging for different types of motion events within the same language when options in addition to the typologically preferred one are allowed.

In the present study, we attempt to fill these gaps in understanding how children learn to map semantic elements onto syntactic structures. We examine elicited narrations from 3-year-old children learning three typologically different languages English, Turkish, and Japanese - which differ in the syntactic structures they use in expressing basic semantic elements of motion events (i.e., English is a satelliteframed language and Turkish and Japanese are verb-framed languages). We focus on data from 3-year-olds because our interest is in syntactic packaging and younger children do not yet have advanced enough syntax to consistently include Manner and Path together in one utterance. The elicited narrations are based on short video clips of motion events in which Manner and Path are both salient, thus encouraging participants to use both elements as much as possible. We also examine one situation in which English-speaking adults use syntactic packaging options other than the typologically preferred construction depending on the degree of causality evident in the relationship between Manner and Path, to determine whether children are sensitive to such subtle differences in speech patterns at age 3. In each of these domains, we explore the extent to which universal and language-specific patterns play a part in syntactic packaging of semantic elements of space in early language development. 


\subsection{Development of spatial language: Contributing factors}

Two views have been proposed in the field of language development regarding how children learn the lexical and syntactic structures to express semantic elements of space: a "universal" hypothesis claiming that children have early default patterns crosslinguistically, and a "language-specific" hypothesis claiming that children follow the grammatical patterns of their native language from their earliest productions. Although these were originally positioned as opposing views, such a clear dichotomy is unlikely. We rather ask how much influence from each is evident in the acquisition process, and what the nature is of universal defaults that persist well beyond infancy (into the fourth year of life).

A linguistic approach to the universal hypothesis, put forth by Bowerman (1982), asserts that children across languages have certain syntactic preferences in their early productions. Specifically, she suggests that children have an initial strategy of isolation or differentiation of semantic elements. Imagine a scene in which a boy holds a ball at the top of a ramp and then lets go such that the ball rolls down the ramp. An adult speaker of English might describe this scene by saying he rolled the ball down the ramp, conflating the manner of motion and the cause of motion into one verb. A child, according to Bowerman, would prefer to express overtly the covert Cause, producing an utterance such as he made the ball roll down the ramp. According to this hypothesis, then, children have an early preference for mapping each semantic element onto a different lexical item or syntactic structure. Only later in development do they begin to follow language-specific norms of conflating certain semantic elements into one lexical or syntactic item.

Such linguistic universal preferences are often attributed to hypothesized uniform cognitive conceptualizations regardless of the language spoken, following the Piagetian assumption that (spatial) cognitive ability is a prerequisite for and precedes the development of (spatial) language. It has been found that children know a great deal about space and spatial relations among objects and motion events long before they learn to speak (Gibson, Owslwy, \& Johnston, 1978; Hespos \& Spelke, 2004; Leslie, 1982; Needham \& Baillargeon, 1993; Piaget \& Inhelder, 1956; Spelke, Breilenger, Macomber, \& Jacobson, 1985). Infants of 7-15 months are also able to detect changes in Manner and Path (Pulverman, Sootsman, Golinkoff, \& Hirsh-Pasek, 2003; Pulverman \& Golinkoff, 2004) and categorize events on the basis of Manner or Path (Pruden, Hirsh-Pasek, Maguire, \& Meyer, 2004), thus suggesting that they can extract individual elements of a motion event from an event as a whole. Later in development, the semantic structures and the grammatical forms of the language map onto these cognitive categories. For example, even though in English, Italian, Serbo-Croatian, and Turkish the numerous adpositions expressing various spatial relations in a given language are equally complex in terms of linguistic structure, the mastery of these spatial terms follows a certain concept-driven sequence over a long period of developmental time (Johnston, 1985; Johnston \& Slobin, 1979). These findings fit Slobin's (1973, 1985) cognitive prerequisites hypothesis for language development. According to this hypothesis, children do not simply acquire the structures of their language, but rather their acquisition is guided by universal perceptual 
and cognitive categories. Later in development, the semantic structures and the grammatical forms of the language map onto these cognitive categories.

However, crosslinguistic differences have challenged the idea that cognitive prerequisites or linguistic default preferences alone guide the learning of spatial language, and recent studies have found evidence in favor of the language specificity hypothesis. This research has shown that children learn language-specific patterns of spatial relations as early as 14 months (i.e., when they first use spatial words productively), suggesting that language-specific semantic structures are a significant force in directing the way language itself is learned, rather than language learning being guided primarily or only by cognitive prerequisites or linguistic defaults (Bowerman, 1996; Choi \& Bowerman, 1991; Gentner, 1982; Imai \& Gentner, 1993; Tardif, 1996).

Although these two views have been presented historically as opposing views, it is by now evident that children are influenced to some degree by each of universal conceptualization, universal linguistic preferences, and language-specific patterns in learning to map semantic elements onto lexical and syntactic structures. Relatively little research has explored, however, how these universal and language-specific influences intertwine in development. Specifically, although we know that language-specific influence is exerted early on, we know less about what type of universal linguistic influences persist, especially in situations where semantic elements map onto complex syntactic structures.

\subsection{Learning to talk about motion events}

Motion events are an excellent area for investigating child language development since the lexicalization and syntactic packaging of semantic components of motion events differs substantially across languages (Slobin, 1996; Talmy, 1985). A motion event consists of several semantic components including Path, Manner, Ground and Figure (Talmy, 1985). Path refers to the trajectory or directionality of a translational motion of a Figure (a moving entity) which, in the most elaborated sense, moves from a source to a goal through some medium, passing one or more milestones. Ground refers to an explicit feature of the physical environment serving as source, medium, milestone, or goal. Manner refers to factors such as the motor pattern of the movement of the Figure, the rate of movement, and the degree of effort involved in the movement.

According to Talmy, languages belong to three typologically different groups in terms of how they lexically and syntactically encode these basic elements of motion events. Satellite-framed languages (e.g., English, German, and Russian) conflate Motion with Manner in the main verb and express Path using verb particles or satellites (e.g., English: fly in, out, and down). Verb-framed languages (e.g., Japanese, Spanish, Turkish, and Semitic languages) conflate Motion with Path in the main verb (e.g., Turkish: gir 'enter', çık 'exit', in 'descend'), and express Manner in the subordinated verb (e.g., Turkish: uçarak çıktı 'exited flying'). The third group of languages conflates Motion with Figure in the main verb (e.g., Atsugewi: -qput- 'loose dry dirt moves'). These differences in lexicalization patterns allow investigation of whether there are differences in the acquisition of these forms crosslinguistically. 
Slobin and his colleagues have investigated how children of different languages learn these different lexicalization patterns that encode the semantic elements of motion events. Özçalişkan and Slobin (1999) compared Turkish- and Spanishspeaking children's acquisition of motion event expressions with that of Englishspeaking children, using narrations of the wordless picture book Frog, Where are You? (Mayer, 1969). They found that, as early as 3 years of age, children are tuned to the language-specific lexicalization patterns of their language. While children learning verb-framed languages (Turkish and Spanish) use more Path verbs in their speech (e.g., exit), English-speaking children learning a satelliteframed language use more Manner verbs (e.g., $f l y$ ). According to Slobin (2003), these findings are mainly a consequence of how Manner is lexicalized in the two types of languages. Since satellite-framed languages do not prefer to encode Path in the main verb, this slot is available for Manner verbs (e.g., English: the bird flew out of the hole). These findings have been replicated for children learning English (satellite-framed) and Korean (verb-framed) using a different set of stimuli - seven short video clips depicting real people walking and running in various locations (Oh, 2003). Both adult and 3-year-old English speakers used significantly more Manner verbs, and significantly fewer Path verbs, than their Korean counterparts in narrating the clips. Similar results have also been found for slightly older child (aged 4-12) and adult speakers of English (satellite-framed) and Greek (verbframed) narrating individual pictures containing both Manner and Path from the frog story books (Papafragou et al., 2002). Finally, Choi and Bowerman (1991) have investigated the emergence of Manner and Path expressions in spontaneous data from two English- and eight Korean-speaking children from the age of 14 months. English-speaking children exhibited very early use of Path satellites (e.g., down, up) in single-word utterances around 14-16 months, Manner verb expressions between 17 and 18 months, and combinations of Manner and Path from 19 months. Korean-speaking children also used Path expressions in single word utterances by 14 months, with the verbs kkita 'interlock, fit tightly' and ppayta 'un-interlock, remove from tight fit' emerging first. However, their first uses of Manner verbs (21 months) and combinations of Manner verbs with Path verbs (sometime after 24 months) came much later than those of their English-speaking counterparts (note that Manner-Path combinations are not common in adult Korean). Further, the first uses and (over)extensions of Path expressions in the two languages reflected language-specific semantic categorizations (vertical motion for English, fitting relationships for Korean) rather than a universal conceptual category, even though the children were talking about similar events. Choi and Bowerman conclude that "children are guided in constructing spatial semantic categories by the language they are exposed to" (p. 110).

\subsection{Present study}

The above-mentioned studies on the development of Manner and Path expressions have shown convincingly that children at 3 years of age follow language-specific patterns in their lexicalization of Manner and/or Path and which information 
is typically expressed in discourse. However, this research has not looked systematically at how children package Manner and Path together in syntax. In fact, many of the existing studies have focused on situations in which the Manner of motion has been optional rather than mandatory and salient in the context (e.g., in Frog Story narratives in Özçalişkan \& Slobin, 1999; and in spontaneous speech in Choi \& Bowerman, 1991). In cases where both Manner and Path of motion are salient and occur simultaneously, children speaking verb-framed languages have to encode Manner as well as Path in their speech to describe such events. Thus, they have to learn how to syntactically package Manner and Path together. Examining syntactic packaging will expand our understanding of how children learn to encode motion events in speech by looking at a more complex level of linguistic expression. In addition, we expect that universal linguistic influences, if present at all, may persist longer in more complex linguistic tasks, and thus may be visible to some extent at the level of syntactic packaging even though they were no longer evident at the level of lexical packaging and information choice in discourse.

The present study, therefore, investigates how children speaking satellite-framed (i.e., English) versus verb-framed languages (i.e., Japanese, Turkish) use the different syntactic constructions that allow them to package Manner and Path together in their speech. Linguistically expressing Manner and Path is a classic linearization problem in Levelt's (1989) sense. There is no natural order between Manner and Path; in fact, they are simultaneous aspects of an event. However, languages typically encode Manner and Path in separate lexical items, and they need to be ordered and, more importantly, to be in a particular syntactic relationship with each other. How do children tackle this linearization problem? Thus, one main question we ask is whether English-, Turkish-, and Japanese-speaking children at age 3 exhibit only language-specific patterns, or do they show any similar ways of syntactically packaging information (not typical to adult speakers of their languages) that might be indications of a universal linguistic influence?

When expressing in speech Manner and Path components that occur simultaneously in a motion event, adult English, Turkish, and Japanese speakers prefer quite different syntactic constructions (even though all the constructions are grammatically available to speakers of all three languages). Imagine a scene which we call the ROLL + DESCEND event. In this scene, a round red smiling tomato comes into view at the top of a hill and then rolls down the hill. Manner (i.e., rolling) and Path (i.e., descending) occur simultaneously in the event, but these two components of the event are lexicalized and syntactically packaged differently in English (satellite-framed) on one hand, and in Turkish and Japanese (verbframed) on the other (Kita \& Özyürek, 2003; Talmy, 1985). English speakers typically encode the event using only one verb with a satellite, resulting in a tight packaging of Manner and Path as indicated by the square brackets in (3). Turkish (4a) and Japanese (4b) speakers typically use two verbal elements within a matrix-subordinate construction to encode Manner and Path of a motion event, resulting in a somewhat less tight syntactic packaging of Manner and Path. As English translations for the Japanese and Turkish examples indicate, a matrix- 
subordinate construction is also possible, though atypical, in English. Similarly, Japanese and Turkish can, under some special circumstances, express Manner and Path within one clause. For example, an adverbial expressing Manner can be combined with the main verb expressing Path (examples will be described in detail in the Section 2).

(3) He [rolls down] the hill.

(4) a. [Yuvarlan-arak] cadde-den [in-iyor]. roll-Connective street-Ablative descend-Present '(He/she/it) descends on the street while rolling'.

(4) b. [Korogat-te] saka-o [ori-ru]. roll-Connective slope-Accusative descend-Present '(He/she/it) descends the slope while rolling'.

In addition, all three languages occasionally use an even looser packaging of Manner and Path by expressing each in a separate sentence with no clause linking, as shown in an example from English in (5).

(5) He [went down] the hill. And he [was rolling] at the same time.

Even though languages differ mainly with respect to preferred syntactic packaging of Manner and Path, it is not unlikely that a given language will also offer options that do not fit the typological patterns. For example English tends to encode different motion event types with different syntactic packaging patterns (i.e., when the Manner causes the change of location versus when the Manner is incidental to the change of location of the moving Figure in intransitive motion; Kita, Özyürek, Allen, Brown, Furman \& Ishizuka, submitted for publication), whereas Turkish and Japanese do not encode the differences in these two event types. This finding has been tied to Goldberg's (1997) theory, based in Construction Grammar, that accounts for the conditions in which English verbs enter into argument structure constructions. According to Goldberg, a verb can appear in an argument structure construction when the meaning of the verb is causally related to the meaning of the construction. This theory predicts, and we have found in previous work, that, in English, Manner and Path are more likely to be expressed in one clause with a Path-denoting particle or preposition if they are causally related (e.g., in a change of location construction such as the ball jumped up the stairs, where the jumping of the ball causes the change of location of the ball). However, in events in which the Manner does not cause a change of location (e.g., a ball rotates while falling down from a window), Manner and Path are more likely to be expressed in two verbal clauses instead of one. We call the first type of events "Manner-Inherent" and the latter "Manner-Incidental". Thus, in the present study we also investigate a second question: whether or not English-speaking children's early speech is sensitive to these differences in syntactic encoding of different motion event types. 


\subsection{Predictions}

By the age of 3, relatively advanced in language development, we expect substantial evidence of language-specific patterns in syntactic packaging of Manner and Path. However, two possibilities can be entertained with regard to the influence of universal patterns in relation to the differences laid out. One possibility is that, unlike the early language specificity of lexical items (e.g., Choi \& Bowerman, 1991), children may show some influence from universal linguistic patterns even as late as age 3 because of the more challenging nature of the linguistic task. In this case, we would expect children from all three languages in our study to show some preference for one particular way of mapping semantic elements onto syntactic frames that is not necessarily consistent with adult patterns across the three languages. Given Bowerman's (1982) suggestion that children have a general strategy of isolation or differentiation of semantic elements, we might expect, for example, that all children would prefer two independent clauses to express Manner and Path (e.g., he rolls and he goes down) instead of one clause with a Manner verb and Path satellite (e.g., he rolls down).

However, another possibility is that children are so sensitive to the language-specific packaging of motion events that they no longer show any influence of universal patterns. (It is also possible that no universal patterns exist in the domain of syntactic packaging of motion events even at the beginning, but our data are taken too far along in the acquisition process to say anything about the initial state of development.) In this case, we would expect English-speaking children to use one-clause [Manner verb + satellite] constructions, and Turkish- and Japanese-speaking children to use two-clause [Manner verb] + [Path verb] constructions from the beginning, and would not expect major developmental shifts across ages. Such a pattern would be consistent with the language-specific preferences discussed earlier with relation to lexical choices around motion events (e.g., Özçalişkan \& Slobin, 1999). Previous work in some domains of syntax acquisition also shows that language-specific effects are visible early on. For example, the timing of acquisition of the passive structure is strongly affected by language-specific factors such as compatibility of the underlying syntax of passives with other syntactic structures in the language, frequency in input, and discourse factors in use of the structure (Allen \& Crago, 1996; Demuth, 1990; Pye \& Quixtan Poz, 1988). Note that the presence of two-clause matrix-subordinate structures in the child data may also be affected by syntactic complexity. Spontaneous speech studies show that the syntactic mechanisms to produce such structures emerge between 3 and 4 years in the languages in question (Aksu-Koç \& Slobin, 1985; Bloom, Lahey, Hood, Lifter, \& Fiess, 1980; Clancy, 1985; Clancy, Jacobsen, \& Silva, 1976; Clark, 2003), so the children in our study may not yet have full mastery of them.

With regard to children's sensitivity to differences in syntactic encoding for different motion event types in English, we predict the following. If children are already fully attuned to language-specific patterns, then we expect English-speaking children to use different types of syntactic packaging for different types of events while Japanese and Turkish children do not. However, if we find children to be still evidencing 
some universal influence at the age of 3 , then we expect the choice of syntactic encoding types across languages to look similar regardless of the type of events.

We test these predictions using narrations by 3-year-olds and adults of motion events involving both Manner and Path. To elicit syntactic constructions where both elements are used, we designed stimulus materials which contain simultaneous and salient occurrences of Manner and Path, as well as two types of relations between the two components (i.e., Manner causing change of location vs. Manner incidental to change of location). We asked the participants to tell in narrative form what they saw in the stimulus video clips. Consistent with our focus on syntactic packaging, we analyze only those narrations in which both Manner and Path are mentioned. In the first analysis of the data, we determine the type of syntactic packaging that each group of participants uses to encode Manner and Path together in their descriptions, and ask whether the choice of packaging type varies with language or age. The second analysis examines whether the motion event type (i.e., Manner-Incidental vs. Manner-Inherent) affects the packaging of Manner and Path, and, if so, whether children speaking different languages are sensitive to these differences at an early age in a similar way to their adult counterparts. These patterns will be revealing about universal and language-specific influences on how children learn to map semantic elements onto syntactic patterns at least in the domain of motion events.

\section{Method}

\subsection{Participants}

Participants in the study were 40 native speakers of Turkish, 40 native speakers of Japanese, and 40 native speakers of English. Twenty of each group were adults ranging in age from about 18 to 40, all current or recent university students in either Istanbul (Turkish), Tokyo (Japanese) or Boston (English). The remaining 20 participants in each group were children. All three groups of children had similar mean ages (Turkish 3;8, Japanese 3;10, and English 3;8) and age ranges (Turkish 3;6-4;0, Japanese 3;5-4;2, and English 3;3-4;3), and all were tested in preschools in the cities just mentioned.

\subsection{Materials}

Data were collected by elicitation, using a set of 10 video clips depicting motion events involving simultaneous Manner and Path (Özyürek, Kita, \& Allen, 2001). Five Manners and three Paths were depicted, yielding the following combinations: JUMP+ASCEND, JUMP+DESCEND, JUMP+GO.AROUND, ROLL+ASCEND, ROLL+DESCEND, ROTATE+ASCEND, ROTATE+DESCEND, SPIN+ASCEND, SPIN+DESCEND, and TUMBLE+DESCEND. The Manner JUMP involves an object moving vertically up and down (always moving along a flat or inclined surface), ROLL involves an object turning on its horizontal axis (always moving along an inclined surface), ROTATE and TUMBLE both involve an object turning on its horizontal axis (always moving vertically through the air), and SPIN involves an object turning on its vertical axis (always moving along an 
inclined surface). Note that the terms JUMP, DESCEND, and so forth are idealized characterizations of the events; participants used these terms as well as many others in their narrative descriptions.

Each video clip was between 6 and $15 \mathrm{~s}$ in duration, and had three salient components: an entry event, a target motion event, and a closing event. The target motion event is the portion of the clip that includes the relevant Manner and Path, and is the focus of our analysis. All clips involved a round red smiling character and a triangular-shaped green frowning character, moving in a simple landscape. Participants chose their own names for the characters; we refer to them here as Tomato Man and Green Man. As an example, the ROLL+ASCEND clip goes as follows. The initial landscape on the screen is a large hill ending in a cliff which drops off to the sea; Tomato Man is located at the base of the hill. Green Man enters the scene from the left and bumps into Tomato Man [entry event], then Tomato Man rolls up the hill [target motion event], and finally Tomato Man falls off the cliff into the ocean and bobs up and down [closing event].

The events depicted by the clips were constructed so as to be one of two event types, following Goldberg (1997) and further elaborated in Kita et al. (submitted for publication). The first type includes events in which the Manner is inherent to the Path in that it causes or enables the Figure to change location, such as a spherical object rolling down a slope. The second type includes events in which the Manner is incidental to the Path and thus the Manner of motion does not affect the change of location of the Figure, such as a triangular object spinning on its vertical axis while going up a slope. The five clips depicting the Manners JUMP and ROLL fall into the Manner-Inherent group, while the five clips depicting the Manners rotate, sPin, and tumble fall into the Manner-Incidental group. Fig. 1 gives a sequence of stills from one Manner-Inherent clip (ROLL+DESCEND) and one Manner-Incidental clip (ROTATE+DESCEND).

\subsection{Procedure}

Participants were tested individually in a quiet space at their university or other educational institution (adults) or preschool (children). All interactions were videotaped for later coding and analysis. The procedure had two parts. During the warm-up phase, the experimenter showed participants a typical scene from a clip and introduced them to the characters and the landscape. She explained that they would see a series of clips on a computer screen depicting adventures of Tomato Man and Green Man, and that, after each one, they should recount the clip to a listener (one of our research assistants) who purportedly had not seen it. She then gave them two practice rounds with clips involving motion events like those in the test clips. Each clip was played twice, with only a blank frame visible at the completion of the clip. She then asked the participant to tell the listener what happened in the clip, and particularly encouraged them to give information about the target motion event if they did not spontaneously do so.

In the testing phase, the experimenter presented the 10 test clips for the participant to narrate, following the same format as in the warm-up phase. If participants did not mention the target motion event in their narration, either the experimenter or 

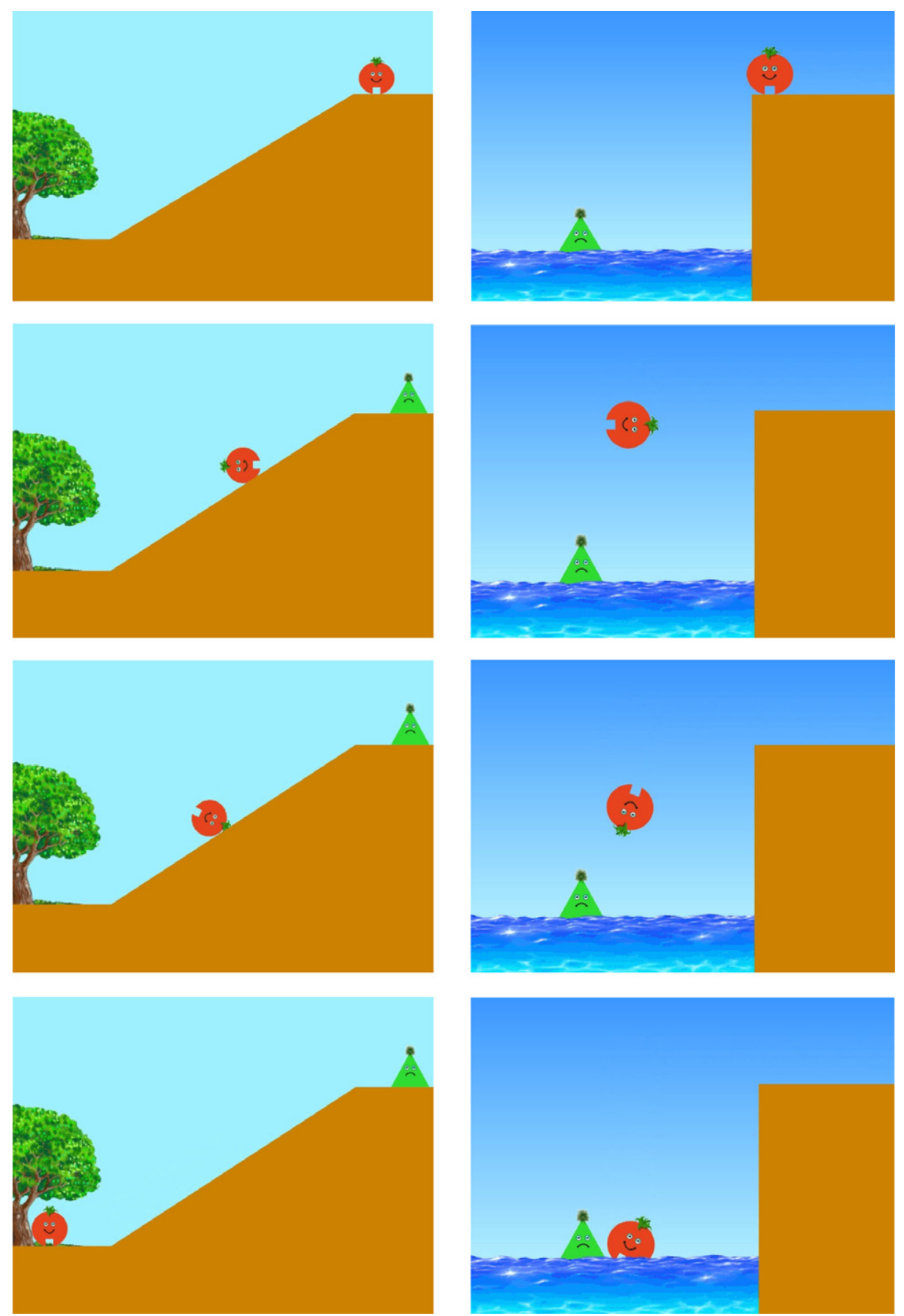

Fig. 1. Selected stills from Manner-Inherent (ROLL+DESCEND, on the left) and Manner-Incidental movies (ROTATE+DESCEND, on the right). 
the listener encouraged them to do so with a question grounded in either the entry event (e.g., What happened after Green Man bumped into Tomato Man?) or the closing event (e.g., What happened before Tomato Man fell off the cliff?). Crucially, this question did not focus explicitly on either Manner or Path. Each of the 10 clips was narrated in turn.

\subsection{Transcription}

All speech relevant to the target motion events (i.e., the portion of each event containing the relevant Manner and Path) was transcribed by native speakers of the relevant language into MediaTagger, a video-based computer program (Brugman \& Kita, 1995). Note that we did not transcribe any speech that described exclusively the entry event, the closing event, or the setting of the scene. The relevant speech for each participant was segmented into "sentences", which we define here as a matrix clause plus its subordinates if any. Examples are shown in (6), with sentence segmentations indicated by square brackets. The attribution for each example indicates the subject group (e.g., EA = English-speaking adult, EC = English-speaking child), the subject number (e.g., EA01 = subject 01 in the EA group), and the name of the clip which was the stimulus for the sentence (e.g., ROLL+ASCEND).

(6) a. [He rolled up the hill.]

(EA01, ROLL+ASCEND)

b. [And he is spinning as he goes down the hill.]

(EA16, SPIN+DESCEND)

Two matrix clauses separated by a coordinating conjunction (i.e., and, but, and or for English, and their equivalents in the other two languages) are considered two sentences, as seen in (7).

(7) [The Red Guy went down] [and it went in circles].

(EC31, ROLL+DESCEND)

Many participants used more than one sentence to describe a given target motion event; all the relevant sentences produced were included in the database. We refer to the full set of sentences used by one participant to describe a particular target motion event as a "target-event description".

The adult description for the ROTATE+DESCEND clip given in (8) illustrates this process. The speaker uttered everything in (8) as his description of the clip. Only the portion describing the target motion event of the Tomato Man rotating down into the water (i.e., the target-event description) was transcribed into MediaTagger, as indicated in (8) by curly brackets. The target-event description was then divided into three sentences, as indicated by square brackets.

(8) There's a ledge on the right and Triangle Man is floating in the water on the left. Tomato Man slides off sort of Wile E. Coyote style, where he does not just fall straight off, but goes about halfway in the air \{[and then falls down]. [So he spins down,] [spins down]\} and lands next to Triangle Man.

(EA07, ROTATE+DESCEND) 
Several types of sentences were then excluded from analysis: those which were not fully intelligible, those which were interrupted before completion, those which resulted from experimental error, and those which were about the target event but contained no reference to the specific Manner or Path in the clip being described.

To establish reliability of the identification and segmentation of sentences, $20 \%$ of the data were independently processed by a second coder who was a native (Turkish, Japanese) or native-like (English) speaker of the relevant language. For each clip, the second coder identified the stretch of discourse describing the target event and segmented it into sentences. When the second coder identified and segmented the same sequence of words as the original coder (disregarding discourse markers and pronouns), it was considered an agreement between the two coders. The percentages of the original coder's sentences with which the second coder agreed were as follows: EA, 92\%; JA, 88\%; TA, 88\%; EC, 100\%; JC, 85\%; and TC, 92\%. Disagreements were resolved by accepting the coding of the initial coder.

\subsection{Coding}

Three structural patterns of packaging Manner and Path in speech were distinguished: Tight (both elements in one sentence with one matrix clause), Semi-Tight (both elements in one sentence, but with one in a matrix and one in a subordinate clause), and Loose (each element in a distinct sentence). Each target-event description was coded as containing one or more exemplars of each of these three packaging types. Note that target-event descriptions which included two types of packaging (e.g., one Tight sentence and one Semi-Tight sentence) were counted in analyses as instances of both types. Target-event descriptions which contained two instances of the same type of packaging (e.g., two Tight sentences) were counted as only one instance of that type.

In this coding, Manner refers to the secondary movement (rotation along different axes, or jumping) of the Figure that co-occurs with the translational movement in the target events. Path refers to the directionality or trajectory specifications for the translational movement. Examples are given from English for ease of reading, except where the construction is specific to either Japanese or Turkish.

\subsubsection{Tight packaging of Manner and Path}

The category "Tight" denotes a tight packaging of both Manner and Path in one mono-clausal sentence, typically involving one verb and one closely associated nonverbal phrase. Sentences coded as Tight differ somewhat across languages and age groups. English Tight sentences include Manner verbs followed by directional Path particles or prepositional phrases (9a), Manner verbs plus further description of the Manner followed by directional Path particles or prepositional phrases (9b), phrases describing Manner followed by a directional Path particle or prepositional phrase (9c), and Manner verbs followed by a directional Path particle with further description of the Path (9d). One child used a construction in which Manner was represented by onomatopoeia and Path by a directional particle (9e); although no adult produced a similar construction, it is not ungrammatical. 
(9) a. He rolled up the hill.

(EA01, ROLL+ASCEND)

b. And the Apple rolls three times counterclockwise down. (EA25, ROLL+DESCEND)

c. And he did his little two-step down the hill.

(EA03, SPIN+DESCEND)

d. And Triangle Man hops all the way around the tree. (EA24, JUMP+GO.AROUND)

e. The other one boinged around the tree.

(EC09, JUMP+GO.AROUND)

Tight sentences also occurred in Turkish and Japanese, although they were rarely used by adults. In Turkish, two constructions were coded as Tight. The first includes a Manner verb with a postpositional directional Path phrase, but crucially no Path verb (10a). The second, used predominantly in child speech, contains a Path verb but expresses Manner with onomatopoeia rather than with a verb (10b).

(10) a. Domates adam aşă̆ yuvarlan-lyor tepe-den tomato man downness roll-Present hill-Ablative 'Tomato Man rolls down the hill'.
aroundness-Possessive-Locative
(TC01, JUMP+GO.AROUND)

(TA14, ROLL+DESCEND)

In Japanese, three types of constructions were coded as Tight. The first, like Turkish (10a), includes a Manner verb with a postpositional directional Path phrase, but crucially no Path verb (11a). The second includes a compound verb consisting of a Manner verb and a Path verb (11b). Although the semantic compositionality within the compound is relatively transparent, this type of compounding is not a productive process in the language. Thus, such compound verbs can be considered single lexical items, and are classified as Tight. Finally, the third Tight sentence type in Japanese consists of a Manner mimetic (sound-symbolic word) and a Path verb, crucially with no Manner verb, as shown in (11c). This construction was rarely produced by adults, but was quite frequent in the child narrations.

$$
\begin{array}{ll}
\text { a. Saka-o } & \text { korogat-te. } \\
\text { slope-Accusative } & \text { roll-Connective } \\
\text { '(He/she/it) rolls (down) the slope'. }
\end{array}
$$

(JA13, ROLL+DESCEND)
b. Saka-o
koroge-ochi-te
slope-Accusative roll-fall-Connective
'(He/she/it) roll-falls the slope.'
c. Guruguru-tto
Mimetic(rotation)-Complementizer
ue-ni
'(He/she/it) ascends guruguru [rotatingly] to the top'.
agat-te.
ascend-Connective

(JA06, ROLL+DESCEND)

(JC05, ROTATE+ASCEND)

\subsubsection{Semi-tight packaging of Manner and Path}

The category "Semi-Tight" denotes a semi-tight packaging of Manner and Path in one sentence, with each of these expressed by a separate verbal element, one subordinated to the other. In English, the subordinated form can be either a fully tensed verb (12a) or a progressive participle functioning as an adverbial (12b). 
(12) a. He spins in circles while he's going down.

(EA18, SPIN+DESCEND)

b. Triangle Man ascends the hill twirling.

(EA20, SPIN+ASCEND)

In Semi-Tight constructions in Turkish, the Manner verb is subordinated to the main Path verb with the use of a connective - mostly -arak as in (13a), and very rarely -ip. Another possibility is to use a reduplicated Manner verb functioning as an adverbial and subordinated to the main Path verb, as in (13b).
a. Dor
Domates adam yuvarlan-arak yokuş-u
tomato man roll-Connective hill-Accusative
'Tomato man descended the hill while rolling.'
in-di.
descend-Past
b. Üçgen döne döne çık-tı triangle turning turning ascend-Past
'Triangle ascended turning turning.'
(TA02, ROLL+DESCEND)

(13)

In Japanese Semi-Tight constructions, like in Turkish, the Manner verb is subordinated to the main Path verb with the use of a connective (-nagara or -te). A mimetic (sound symbolic word) is frequently used as an adverbial to the Manner verb. Examples are given with -nagara (14a) and -te (14b).

\begin{tabular}{|c|c|c|c|}
\hline (14) & $\begin{array}{ll}\text { a. } & \text { Kurukuru } \\
& \text { Mimetic(rotation) }\end{array}$ & $\begin{array}{ll}\text { mawari-nagara } & \text { saka-o } \\
\text { rotate-Connective } & \text { slope-Accusative }\end{array}$ & $\begin{array}{ll}\text { ori-te } & k i \text {-te } \\
\text { descend-Connective } & \text { come-Connective }\end{array}$ \\
\hline & '(It) comes descending & as (it) rotates kurukuru [rotatingly]'. & (JA29, SPIN+DESCEND) \\
\hline (14) & $\begin{array}{l}\text { b. Guruguru } \\
\text { Mimetic(rotation) }\end{array}$ & $\begin{array}{ll}\text { mawat-te } & \text { ori-te } \\
\text { turn-Connective } & \text { descend-Connective }\end{array}$ & \\
\hline
\end{tabular}

\subsubsection{Loose packaging of Manner and Path}

Many participants used more than one sentence to describe the target event. Descriptions were coded as having "Loose" packaging of Manner and Path if they contained at least one Path-Only sentence as well as at least one Manner-Only sentence, as shown in (7). The packaging was considered Loose because the two motion event elements are expressed in two separate sentences.

"Manner-Only" sentences express only a Manner element (i.e., no Path). Sentences coded as Manner-Only in English include simple Manner verbs (15a), Manner verbs plus some further description of the Manner (15b), and phrases which describe the Manner without a Manner verb (15c). Children occasionally used a light verb in combination with onomatopoeia in place of a Manner verb (15d) and these sentences were coded as including Manner.

(15) a. And the Red Guy twirled.

b. And then tumbles head over heels.

(EC06, ROLL+ASCEND)

c. And does a little couple of rounds.

(EA19, ROTATE+DESCEND)

d. The Circle went boop boop.

(EA05, ROTATE+DESCEND)

(EC34, JUMP+GO.AROUND)

Japanese and Turkish Manner-Only sentences include similar constructions to the English ones shown in (15a), (15b), and (15d), but none like (15c). In Japanese, as noted earlier, a special class of sound-symbolic words called mimetics is often used to express Manner. Mimetics can appear in Manner-Only sentences with a Manner verb (16a) or with a light verb (16b). 
(16) a. Guruguru Mimetic(rotation) '(He/she/it) was turni

(16) b. Kururin-tte Mimetic(rotation)-Complementizer do-Connective '(He/she/it) does kururin [rotatingly]'. mawat-te-ta.

turn-Connective-Imperfect:Past

(JC16, SPIN+ASCEND)

(JC22, ROLL+ASCEND)

"Path-Only" sentences express only a Path element (i.e., no Manner). In English, sentences coded as Path-Only include the light Path verb go followed by directional Path particles or prepositional phrases (17a), other Path verbs optionally followed by directional Path particles or prepositional phrases (17b), and phrases which describe the Path $(17 \mathrm{c})$.

(17) a. He goes up a hill.

(EA27, ROLL+ASCEND)

b. It fell.

c. Does a cannonball.

(EC11, SPIN+DESCEND)

(EA14, ROTATE+DESCEND)

In Turkish, sentences coded as Path-Only include light Path verbs (come and go) as in (18a) and other Path verbs as in (18b), both with optional postpositional phrases that include spatial nouns specifying the source or the goal of the Path.

(18) a. Aşă̆l-ya gel-iyor.

downness-Dative come-Present

'(He/she/it) comes down'.

(TA12, ROLL+DESCEND)

(18) b. Sonra yukarı çık-tı.

then upness ascend-Past

'Then (he/she/it) ascended (to) the upness'.

(TC02, JUMP+ASCEND)

Finally, sentences coded as Path-Only in Japanese were similar in structure to the Turkish examples in (18a) and (18b); like in Turkish, the postpositional phrase is optional with both verb types. In addition, the Path-Only category in Japanese included sentences with both a light Path verb and another Path verb, as shown in (19).

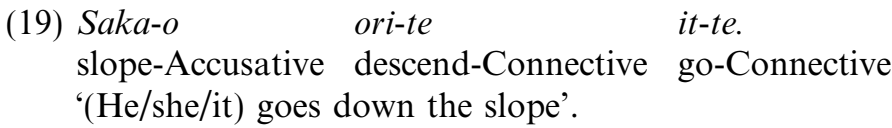

(JA14, JUMP+DESCEND)

\subsubsection{Reliability}

To establish reliability of the coding, $20 \%$ of the data were independently processed by a second coder who was either a native (Turkish, Japanese) or near-native (English) speaker of the relevant language. The second coder judged the category type (i.e., Manner-Only, Path-Only, Tight, and Semi-Tight) for each sentence that had been segmented and transcribed by the original coder. The agreement between coders for this judgment was as follows: EA, 93\%; JA, 98\%; TA, 91\%; EC, 98\%; JC, 91\%; and TC, $96 \%$. Disagreements were resolved by accepting the coding of the initial coder. 


\section{Results}

The analysis was conducted in two parts. In the first analysis, we determined the type of syntactic packaging that each group of participants used to encode Manner and Path together in their descriptions, and assessed whether the choice of packaging type varied with language (English, Japanese, and Turkish) and/or with age (child, adult). The second analysis examined whether the event type of the stimulus (i.e., Manner-Inherent vs. Manner-Incidental) affected the packaging of Manner and Path in the target-event descriptions and, if so, whether this effect varied with language and/or with age. The dependent variable for all analyses is the proportion of target-event descriptions that include at least one exemplar of a particular syntactic packaging type (i.e., Tight, Semi-Tight, or Loose). $T$ tests, ANOVAs (analyses of variance) and, in some cases, Wilcoxon Singed Ranks test are used.

Because we were interested in the patterns of packaging Manner and Path together, only target-event descriptions which expressed both Manner and Path were used in the analyses. Table 1 shows, for each of the six groups of participants, the mean proportion of target-event descriptions which contained solely Manner information, solely Path information, and both Manner and Path information. Note that the target-event descriptions which contain both Manner and Path can include any of those designated as Tight, Semi-Tight, and Loose.

All six groups of participants produced a substantial number of target-event descriptions which expressed both Manner and Path. Notably, however, all three groups of children produced fewer target-event descriptions with both Manner and Path expressed than did the adults (English, $t(38)=6.16, p<.001$; Japanese, $t(38)=7.87, p<.001$; Turkish, $t(38)=10.15, p<.001)$.

\subsection{Does the syntactic packaging of expressions encoding Manner and Path vary with language andlor with age?}

The first analysis examined the types of syntactic packaging that each group of participants used when encoding both Manner and Path in their descriptions, and investigated whether choice of packaging type varied with language and/or

Table 1

Mean proportion (SD) of target-event descriptions in which Only Manner, Only Path, and Both Motion elements are mentioned

\begin{tabular}{lllll}
\hline & Only Manner & Only Path & Both Manner and Path & $\begin{array}{l}\text { Mean number of target-event } \\
\text { descriptions per subject }\end{array}$ \\
\hline EA & $.04(.07)$ & $.12(.12)$ & $.85(.13)$ & $9.95(0.73)$ \\
JA & $.04(.07)$ & $.12(.10)$ & $.84(.09)$ & $9.75(0.72)$ \\
TA & $.02(.04)$ & $.08(.12)$ & $.90(.12)$ & $9.90(0.31)$ \\
EC & $.12(.12)$ & $.37(.22)$ & $.51(.21)$ & $9.70(0.73)$ \\
JC & $.24(.21)$ & $.35(.23)$ & $.41(.23)$ & $8.00(1.84)$ \\
TC & $.18(.16)$ & $.42(.19)$ & $.41(.18)$ & $9.60(0.68)$ \\
\hline
\end{tabular}

Note. EA, English-speaking adults; JA, Japanese-speaking adults; TA, Turkish-speaking adults; EC, English-speaking children; JC, Japanese-speaking children, and TC, Turkish-speaking children. 
with age. Three types of packaging were distinguished: Tight, Semi-Tight, and Loose.

As discussed earlier, we expected adult English speakers to mostly produce Tight constructions, and adult Japanese and Turkish speakers to mostly produce Semi-Tight constructions. If child speakers show no universal influence, then their productions should be similar to the adult ones just specified. If they do show universal influence along the lines suggested by Bowerman (1982), however, then we might expect children in all three language groups to produce significantly more Semi-Tight (for English) or Loose (for all three languages) constructions than their adult counterparts.

To retain enough variability in the data, we excluded data from all participants who did not produce at least three (out of 10) target-event descriptions in which both Manner and Path were expressed. All 60 adult participants produced at least three such target-event descriptions. However, several children from each language group did not, so that data from only 18 English-speaking children, 12 Japanese-speaking children, and 14 Turkish-speaking children were considered for this analysis.

Table 2 shows the mean proportion of target-event descriptions in which at least one instance of Tight, Semi-Tight, or Loose packaging is used in describing motion events when both Manner and Path are expressed.

\subsubsection{Use of Tight syntactic packaging}

Target-event descriptions which include Tight syntactic packaging are used differentially across languages, and between adults and children. An ANOVA with two between-subjects variables, language (English, Japanese, and Turkish) and age (adult, child), showed main effects of both language, $F(2,98)=180.495, p<.001$, and age, $F(1,98)=67.443, p<.001$, as well as an interaction between them, $F(2$, $98)=20.071, p<.001$. Post hoc $t$ tests (with Bonferroni adjustment) among the adult language groups showed that there were more target-event descriptions containing Tight syntactic packaging in English than in either Japanese or Turkish $(p<.001)$. A similar analysis for children revealed that more target-event descriptions with Tight syntactic packaging were used in English than in either Japanese $(p<.05)$ or Turkish $(p<.001)$, and more in Japanese than in Turkish $(p<.01)$. Further post hoc $t$ tests (with Bonferroni adjustment) comparing the child and adult

Table 2

Mean proportion (SD) of target-event descriptions in which at least one instance of Tight, Semi-Tight, or Loose syntactic packaging is used

\begin{tabular}{|c|c|c|c|c|}
\hline & Tight & Semi-Tight & Loose & $\begin{array}{l}\text { Mean number of target-event } \\
\text { descriptions per subject }\end{array}$ \\
\hline EA & $.78(.15)$ & $.14(.14)$ & $.12(.13)$ & $8.45(1.27)$ \\
\hline JA & $.03(.05)$ & $.97(.07)$ & $.03(.05)$ & $8.20(0.89)$ \\
\hline TA & $.01(.03)$ & $.94(.13)$ & $.07(.13)$ & $8.95(1.23)$ \\
\hline $\mathrm{EC}$ & $.82(.19)$ & $.00(.00)$ & $.21(.19)$ & $5.28(2.02)$ \\
\hline $\mathrm{JC}$ & $.56(.24)$ & $.40(.27)$ & $.16(.19)$ & $4.92(1.73)$ \\
\hline $\mathrm{TC}$ & $.22(.22)$ & $.44(.37)$ & $.38(.28)$ & $4.79(1.63)$ \\
\hline
\end{tabular}

Note. EA, English speaking adults; JA, Japanese speaking adults; TA, Turkish speaking adults; EC, English speaking children; JC, Japanese speaking children; and TC, Turkish speaking children. 
groups within each language showed significant differences between Japanese-speaking adults and children $(p<.001)$, and between Turkish-speaking adults and children $(p<.05)$, but no difference between the two age groups in English. Although Japanese- and Turkish-speaking children used more Tight syntactic packaging than their adult counterparts, English-speaking children did not.

These results first of all reveal language-specific differences among the adult languages. English-speaking adults used many more target-event descriptions with Tight packaging than did either Japanese- or Turkish-speaking adults. Further, the developmental differences reveal both universal and language-specific patterns. All children had a tendency to package Manner and Path tightly in speech when these two elements occurred simultaneously in an event, and Japanese- and Turkish-speaking children did so significantly more often than their adult counterparts who rarely used this pattern. (Note that English-speaking adults were already close to ceiling in their production of target-event descriptions with Tight packaging, so it would be difficult for English-speaking children to exceed this level.) This universal pattern is moderated by linguistic differences, however, in that the three child groups produced significantly different proportions of target-event descriptions with Tight packaging: English-speaking children used Tight packaging more than Japanese- and Turkish-speaking children did.

Particularly interesting in the results above is the difference between the Japaneseand Turkish-speaking children and their adult counterparts in the use of Tight syntactic packaging. How do Turkish- and Japanese-speaking children produce Tight syntactic constructions that express both Manner and Path in one verbal clause without using two verbs, given that these are rarely used by adult speakers of those languages? To understand this pattern, we performed a qualitative analysis of the relevant expressions used by Japanese- and Turkish-speaking children. In each language, two types of constructions were used. Turkish-speaking children used a Manner verb with a spatial noun to express Path in about half of the 17 Tight sentences they produced, as shown in (20a). They used a Path verb with onomatopoeia to express Manner in the other half, as shown in (20b).
(20) a. O-nun
etraf-ın-da
zıpla-dl.
it-Genitive aroundness-Possessive-Locative jump-Past
'(He/she/it) jumped around it'.
(20) b. Tak tak in-di
Onomatopoeia descend-Past
'(He/she/it) tak tak descended'.
(TC21, JUMP+GO.AROUND)
(TC04, JUMP+DESCEND)

Japanese-speaking children produced 43 Tight sentences. Virtually all of them (41) consisted of a Path verb plus a mimetic (sound-symbolic word) to express Manner, as shown in (21). Two Tight sentences consisted of a Manner verb and a postpositional Path phrase, like the Turkish example in (20a).
(21) Guruguru-tto
ue-ni agat-te.
Mimetic(rotation)-Complementizer top-Dative ascend-Connective
'(He/she/it) ascends guruguru [rotatingly] to the top'. (JC05, ROTATE+ASCEND) 
Although such sentences are not considered ungrammatical in adult Japanese or Turkish, they do sound unusual and were virtually never used by the adults in our sample. Only three sentences of the type illustrated in (21) were produced by Japanese-speaking adults, and only two sentences of the type illustrated in (20a) by Turkish-speaking adults. Note that it is not the case that the use of mimetics per se distinguishes Japanese children from adults. Mimetics are frequently used in adult Japanese spoken discourse (Kita, 1997). Of the 20 participants in each group, 19 children and 17 adults used mimetics to encode Manner at least once in their targetevent descriptions. Unlike children, adults virtually always combined a mimetic with a Manner verb.

\subsubsection{Use of Semi-Tight syntactic packaging}

We next investigated the developmental patterns for the use of Semi-Tight syntactic packaging across languages (see figures in Table 2). An ANOVA with two between-subjects variables, language (English, Japanese, and Turkish) and age (adult, child), showed main effects of both language, $F(2,98)=128.690$, $p<.001$, and age, $F(1,98)=117.357, p<.001$, as well as an interaction between them, $F(2,98)=13.515, p<.001$. Post hoc $t$ tests (with Bonferroni adjustment) showed that the proportion of target-event descriptions containing Semi-Tight syntactic packaging was higher for both Japanese- and Turkish-speaking adults than for English-speaking adults $(p<.001)$. A similar language effect holds for children, with more target-event descriptions containing Semi-Tight packaging in both Japanese and Turkish than in English $(p<.001)$, mirroring the adult patterns. Furthermore, English-, Turkish-, and Japanese-speaking adults use more target-event descriptions containing Semi-Tight packaging than their child counterparts $(p<.001)$. We assume that the interaction between language and age results from a smaller difference in proportion of target-event descriptions containing SemiTight packaging between English-speaking adults and children than between adults and children of the other two language groups. This is probably the result of a floor effect: the proportion of Semi-Tight structures used by English-speaking adults is so low that the potential for child-adult difference in this language group is very restricted.

These results again reveal both universal and language-specific patterns in development. All children produced significantly fewer target-event descriptions with Semi-Tight packaging than their counterpart adult groups, most likely because of the syntactic difficulty inherent in producing the requisite subordination constructions. However, this universal pattern is moderated by linguistic differences, in that Turkish- and Japanese-speaking children used Semi-Tight packaging more than English-speaking children did, mirroring the adult patterns.

\subsubsection{Use of Loose syntactic packaging}

Finally, we investigated the use of Loose syntactic packaging across languages and ages. A $3 * 2$ ANOVA with language and age as between-subjects variables showed main effects of both language, $F(2,98)=4.990, p<.01$, and age, $F(1$, $98)=28.960, p<.001$, as well as an interaction between them, $F(2,98)=4.160$, 
$p<.05$. Post hoc $t$ tests (with Bonferroni adjustment) showed that the proportion of target-event descriptions containing Loose syntactic packaging was higher for Turkish- than for Japanese-speaking children $(p<.05)$. This unexpected difference may arise because Tight and Semi-Tight constructions are more syntactically complex or unusual in Turkish than in Japanese, so Turkish-speaking children may have more difficulty producing them and thus resort to Loose constructions more frequently. Furthermore, $t$ tests comparing the child and adult groups within each language showed a significant difference for Turkish $(p<.01)$. We infer that the interaction between language and age results from a larger difference in proportion of target-event descriptions containing Loose packaging between Turkish-speaking adults and children than between adults and children for the other two language groups.

These results reveal that Loose syntactic packaging is not the predominant way of packaging Manner and Path for any of the three languages, perhaps because it fails to accurately convey the simultaneous occurrence of the two components of the motion event. Nonetheless, both children and adults do use this packaging occasionally. No language-specific differences were evident in the adult target. Children produce more target-event descriptions with Loose packaging than do adults overall, although this difference is slightly higher for Turkish than for the other two languages.

\subsection{Does event type affect the packaging of Manner and Path in the narration of a motion event?}

The second analysis investigated whether the event type of the stimulus (i.e., Manner-Inherent vs. Manner-Incidental) affected the packaging of Manner and Path in the target-event descriptions and, if so, whether this effect varied with language and/or with age. We expected that when more than one packaging option is relatively common in a language (i.e., English in our study), speakers would tend to choose tighter syntactic packaging (i.e., Tight) to express Manner and Path for events where the Manner is causally related to the Path, and less tight syntactic packaging (i.e., Semi-Tight or Loose) for Manner-Incidental events where the Manner is only incidentally related to the Path. We did not expect any differentiation in packaging for the two event types in adult Japanese or Turkish. The typologically favoured packaging type, Semi-Tight, already expresses the Manner and Path in separate clauses, and could be used to describe Manner-Incidental events. Although Japanese and Turkish speakers might try to produce Tight sentences to emphasize the stronger relationship between Manner and Path when describing Manner-Inherent events, such constructions are not common in the language and thus are likely to be disfavoured.

If children are still evidencing some universal influence at age 3 , then we expect the patterns across languages to look like those expected for the first analysis: all children should produce significantly more Semi-Tight and Loose sentences than their adult counterparts as predicted by Bowerman (1982), and no distinction should be evident between descriptions for the two event types in any of the 
languages. However, if children are already fully attuned to language-specific patterns, then we expect them to produce sentences similar to the patterns just specified for adults (i.e., the English-speaking children should be sensitive to the difference between event types, and the Japanese- and Turkish-speaking children should not).

As in the first analysis, only the target-event descriptions which expressed both Manner and Path were considered. In addition, we excluded data from all participants who did not have at least one target-event description in which both Manner and Path were encoded for each of a Manner-Incidental event and a Manner-Inherent event. All 60 adult participants met these criteria. However, several children from each language group did not produce the requisite number of target-event descriptions of each event type containing both elements. Therefore, data from only 17 English-speaking children, 12 Japanese-speaking children, and 17 Turkish-speaking children were considered.

Table 3 shows the mean proportion of target-event descriptions in which at least one instance of Tight, Semi-Tight, or Loose packaging was used in describing each of the two motion event types, when both Manner and Path are expressed.

\subsubsection{Use of Tight syntactic packaging for different event types}

Within the adult groups, only English speakers used Tight packaging more frequently for depicting Manner-Inherent events than for Manner-Incidental ones. An ANOVA for adult data, with language (English, Japanese, and Turkish) as a between-subjects variable and event type (Manner-Inherent, Manner-Incidental) as a within-subjects variable, showed main effects of both language, $F(2,57)=414.990$, $p<.001$, and event type, $F(1,57)=19.574, p<.001$, as well as an interaction between them, $F(2,57)=12.302, p<.001$. Post hoc $t$ tests (with Bonferroni adjustment) showed a significant difference in use of Tight syntactic packaging for Manner-Inherent versus Manner-Incidental items for English $(p<.01)$, but not for the other two languages.

Separate analyses with non-parametric statistics were done for each of the three child groups, because there were too few instances per subject of target-event

Table 3

Mean proportion (SD) of target-event descriptions in which at least one instance of Tight, Semi-Tight, or Loose syntactic packaging is used, by event type

\begin{tabular}{|c|c|c|c|c|c|c|}
\hline & \multicolumn{2}{|l|}{ Tight } & \multicolumn{2}{|l|}{ Semi-Tight } & \multicolumn{2}{|l|}{ Loose } \\
\hline & M-Inherent & M-Incidental & M-Inherent & M-Incidental & M-Inherent & M-Incidental \\
\hline EA & $.92(.12)$ & $.63(.29)$ & $.05(.11)$ & $.23(.25)$ & $.04(.09)$ & $.20(.23)$ \\
\hline JA & $.04(.10)$ & $.01(.06)$ & $.94(.12)$ & $.99(.06)$ & $.04(.10)$ & $.03(.11)$ \\
\hline TA & $.02(.06)$ & $.00(.00)$ & $.93(.14)$ & $.94(.18)$ & $.08(.19)$ & $.07(.18)$ \\
\hline $\mathrm{EC}$ & $.92(.16)$ & $.69(.40)$ & $.00(.00)$ & $.00(.00)$ & $.12(.21)$ & $.33(.39)$ \\
\hline $\mathrm{JC}$ & $.58(.38)$ & $.39(.37)$ & $.36(.37)$ & $.57(.41)$ & $.18(.29)$ & $.14(.19)$ \\
\hline $\mathrm{TC}$ & $.24(.35)$ & $.13(.30)$ & $.31(.41)$ & $.38(.46)$ & $.45(.38)$ & $.53(.49)$ \\
\hline
\end{tabular}

Note. EA, English-speaking adults; JA, Japanese-speaking adults; TA, Turkish-speaking adults; EC, English-speaking children; JC, Japanese-speaking children; and TC, Turkish-speaking children. 
descriptions which contained expressions of both Manner and Path to perform an ANOVA. Nevertheless, the child patterns mirrored the adult sensitivity to different event types. English-speaking children used Tight syntactic packaging significantly more frequently in target-event descriptions for Manner-Inherent than for Manner-Incidental events (Wilcoxon Signed Ranks Test, $p<.05$ ). This difference was not significant for either Japanese- or Turkish-speaking children.

\subsubsection{Use of Semi-Tight packaging for different event types}

We also analyzed whether Semi-Tight packaging of Manner and Path was used differentially by the adult groups for Manner-Incidental versus Manner-Inherent events. A $3 * 2$ ANOVA with language and event type as variables showed main effects of both language, $F(2,57)=291.585, p<.001$, and event type, $F(1$, $57)=10.662, p<.01$, as well as an interaction between them, $F(2,57)=4.461$, $p<.05$. Post hoc $t$ tests (with Bonferroni adjustment) showed a significant difference in use of Semi-Tight packaging for Manner-Inherent versus Manner-Incidental items for English $(p<.05)$, but not for the other two languages.

English-speaking children did not use Semi-Tight packaging at all in their narratives for either event type. Analysis of children's target-event descriptions in the other two languages, using the Wilcoxon Signed Ranks Test, showed no difference in use of Semi-Tight packaging according to event type for either Turkish- or Japanese-speaking children.

\subsubsection{Use of Loose syntactic packaging for different event types}

Finally, we investigated whether Loose syntactic packaging of Manner and Path was used differentially for Manner-Incidental and Manner-Inherent events. A $3 * 2$ ANOVA for the three adult groups, with language and event type as variables, did not show effects of either language, $F(2,57)=2.854$, or event type, $F(1,57)=3.047$, but the interaction between these two variables was significant, $F(2,57)=4.585, p<.05$. Post hoc $t$ tests (with Bonferroni adjustment) showed a significant difference in the use of Loose packaging for Manner-Inherent versus Manner-Incidental items for English $(p<.05)$, but not for the other two languages.

Child speech shows an identical pattern. English-speaking children used Loose packaging marginally more frequently for Manner-Incidental than for Manner-Inherent events (Wilcoxon Signed Ranks Test, $p=.058$ ), but there was no significant difference in use for either Turkish- or Japanese-speaking children. The marginal significance for English-speaking children is probably due to the smallness of the sample.

These results taken together show that English adult speakers prefer tighter packaging options to talk about Manner-Inherent events than Manner-Incidental events, as expected from Goldberg's (1997) theory described earlier. English-speaking children are also attuned to this language-specific sensitivity, mirroring the adult patterns. In contrast, neither Turkish- nor Japanese-speaking adults or children changed their syntactic packaging options to reflect the difference in the two event types. 


\section{Discussion}

This study investigated how children syntactically package elements of motion events in their speech. We focused on two questions. First, to what extent, if any, do children learning different languages use similar mappings of semantic elements onto syntactic structures, or are they already fully attuned to the language-specific patterns of their native languages by age 3? Second, assuming that 3-year-olds have at least some sensitivity to language-specific patterns, does that sensitivity extend to even very subtle differences such as syntactic packaging preferences according to the type of event described?

Recent research has provided evidence for the emergence of language-specific patterns very early on in the lexicalization of Manner and Path information and their expression in discourse (e.g., Choi \& Bowerman, 1991), and these patterns are quite robust by age 3 or 4 (e.g., Oh, 2003; Özçalişkan \& Slobin, 1999; Papafragou et al., 2002). However, some of this research has been based on motion event descriptions where Manner is not necessarily salient in context or simultaneous with Path in the events depicted (e.g., frog stories, spontaneous speech). Further, this research has not looked systematically at patterns in arguably more advanced areas of language such as syntax, where universal influences (if there are any) may persist longer in development. In the present study, we investigated how 3-year-old children choose to package Manner and Path in syntactic units when both these elements are salient and simultaneous in the depicted event. We found that children learning the three languages under study largely follow language-specific patterns in their packaging, even mirroring very subtle adult preferences in packaging choice. However, some universal patterns are also evident, even at the relatively late age of 3 years.

\subsection{Language-specific patterns in syntactic packaging of Manner and Path at age 3}

Our results support the claim that language-specific patterns are evident in syntactic packaging of Manner and Path at age 3. We found that English-speaking adults typically used Tight syntactic packaging of Manner and Path in their description of motion events, in which Manner is represented as a verb and Path as a non-verbal element which is closely associated to the verb. In contrast, both Japanese-speaking and Turkish-speaking adults typically used somewhat less tight packaging (i.e., Semi-Tight) in which Manner and Path are represented as separate verbal elements, usually in a subordinating relationship. Adult speakers of all three languages also occasionally used Loose syntactic packaging of Manner and Path in which each motion element is represented in its own sentence, without a syntactic relationship between the two elements.

It is important to note that the fact that our stimulus materials included motion events with both Manner and Path being salient and simultaneous made a difference compared to previous studies. For example, Turkish adult speakers used Semi-Tight syntactic packaging $94 \%$ of the time when they mentioned both elements in their target-event descriptions. In contrast, Turkish-speaking adults never used this construction in describing motion events in the Frog Story, which does not include instances 
of simultaneous occurrence of Manner and Path where both are salient (Özçalişkan \& Slobin, 1999; Özyürek \& Özçalişkan, 2000). Consistent with the results of the present study, Özyürek and Kita (1999) also found frequent use of Semi-Tight constructions in cartoon narrations when both Manner and Path were salient and simultaneous.

Children followed the same general patterns as their adult counterparts in terms of syntactic packaging options. Although all children produced target-event descriptions which included Tight packaging of Manner and Path, English-speaking children produced them more frequently than the children in the other two language groups, mirroring the adult patterns. Similarly, Japanese- and Turkish-speaking children produced target-event descriptions with Semi-Tight packaging much more frequently than did English-speaking children, again consistent with the adult patterns. Finally, all three groups of children occasionally used Loose syntactic packaging with no differences across the language groups, as did the adults. The non-frequent use of this construction could be due to the fact that it does not encode the simultaneity of the two elements of the event.

Given these language-specific tendencies, we might wonder why English-speaking children produced as many target-event descriptions with Tight syntactic packaging as their adult counterparts (i.e., the preferred syntactic option for English adult speakers), while Japanese- and Turkish-speaking children produce significantly fewer target-event descriptions containing the packaging option preferred for their language (i.e., Semi-Tight packaging). We believe that the syntactic complexity involved in the two types of structures could be a mitigating factor. Specifically, the Manner verb + Path satellite constructions typical of English Tight packaging are syntactically relatively easy, while the two-verb subordinating constructions typical of Semi-Tight packaging in the other two languages are relatively more difficult to learn. Note that unlike the adult English speakers, the child English speakers did not produce sentences with Semi-Tight packaging.

This hypothesis is consistent with the little available data on the acquisition of conjunctions and biclausal constructions. Based on a study of spontaneous speech data from English, German, Italian, and Turkish, Clancy et al. (1976) report that conjunctions expressing simultaneity are learned relatively late crosslinguistically, sometime between 3;6 and 4;0. Clancy's (1985, pp. 471-475) spontaneous speech data from Japanese agree with this finding. She reports that the first constructions in Japanese using the conjunction of simultaneity common in our data (-nagara) appear after $3 ; 6$. The other common conjunction in our data, -te, first appears close to $2 ; 6$, but it is multifunctional and its earliest uses have been reported to express temporal sequencing and causality rather than simultaneity. Aksu-Koç and Slobin (1985) report that conjunctions expressing simultaneity are also acquired late in Turkish. They give the following time line for acquisition of means of combining clauses to express temporal relations: until age $2 ; 6$ children produce "simple juxtaposition of sentences... without explicit grammatical markers of connection", between $2 ; 6$ and $3 ; 6$ they use "connectives that do not require nominalizations (conjunctions and converbs)", and after age 4;0 they begin to show "more [frequent] use [of] nominalizations for various subordinate clauses" despite "prolonged confusion between 
the various forms" (pp. 846-847). They also note that coordinations requiring one of the verbs to be in a participial form are not mastered until after age 5 .

Our results also revealed evidence of sensitivity to language-specific patterns at a much more subtle level than shown by previous research; 3-year-old children mirror adults' differential use of syntactic patterns for different event types (i.e., Manner-Inherent vs. Manner-Incidental). We found that in English, where speakers freely produce all three syntactic options (i.e., Tight, Semi-Tight, and Loose), adult speakers used Tight syntactic packaging significantly more often for Manner-Inherent events in which the two motion elements are more tightly causally linked than they did for Manner-Incidental events in which the two motion elements are less tightly causally linked. In contrast, they used looser syntactic packaging (i.e., Semi-Tight and Loose) more frequently for Manner-Incidental than for Manner-Inherent events. Englishspeaking children also followed this language-specific pattern. They used Tight syntactic constructions more frequently to describe Manner-Inherent events than Manner-Incidental events. Japanese- and Turkish-speaking adults, in contrast, used Semi-Tight packaging of Manner and Path virtually all the time regardless of the event type. Turkish- and Japanese-speaking children followed this same pattern; unlike English-speaking children, they did not use different syntactic packaging patterns for different event types. These contrastive findings are striking, showing that children are not only sensitive to the predominant packaging pattern used in the input, but also to the subtle conditions under which each packaging option is used in languages in which distinctions between event types are linguistically encoded.

\subsection{Universal patterns in syntactic packaging of Manner and Path at age 3}

In addition to the language-specific syntactic patterns just noted, our results also provide evidence for universal tendencies in how children map semantic elements onto syntactic patterns to talk about Manner and Path occurring simultaneously. The 3-year-olds across the three language groups showed some similar tendencies in their syntactic packaging choices which were not fully consistent with those of their adult counterparts, although, as just discussed, the language-specific patterns are already largely in place.

The most striking universal tendency that revealed itself in our data is that children in all three language groups showed a strong tendency to package Manner and Path tightly in speech, that is within one verbal clause rather than two, when representing events in which Manner and Path occur simultaneously. This Tight packaging occurred in child descriptions more frequently than in adult ones for both Japanese and Turkish (recall that English-speaking adults are almost at ceiling for this pattern), even to the extent that Japanese- and Turkish-speaking children produced rather atypical constructions to achieve Tight syntactic packaging. Furthermore, even when Semi-Tight syntactic packaging is the preferred option for adults, as in Turkish and Japanese, children do not use this construction as often as their adult counterparts.

These results contrast with what we might have expected given Bowerman's (1982) suggestion that children have an initial strategy of isolation or differentiation 
of semantic elements, such as expressing overtly the covert Cause in expressions like he made the ball roll down. In our study, children show the opposite strategy: synthesis of semantic elements. A recent study by Özyürek and Özçalişkan (2000) has also found evidence contradicting Bowerman's findings; they show that Turkish-speaking children produce verbs that conflate both Manner and Path information (e.g., tirman 'ascend climbing') very early on even though these verbs do not fit the typological pattern of Turkish. However, it is important to note that the findings of the present study pertain to a slightly different question than those of either Bowerman (1982) or Özyürek and Özçalişkan (2000) in that we show children's preference for packaging different semantic elements into syntactic units, but not lexical packaging of semantic elements.

Children's initial tendency to package both semantic elements into one verbal clause could be attributed to how children map cognitive and linguistic representations. It may be that children have a universal drive to pursue cohesion between cognitive and linguistic representations of an event. Thus, they may be attempting to map their cognitive representation of simultaneously occurring Manner and Path onto the linguistic structure with some iconicity principle: elements that are close together in cognitive representation should be close to each other in the corresponding linguistic representation. It is also possible that children have certain universal assumptions about what type of information tends to be expressed by a particular syntactic unit, not unlike children's assumptions about word meaning such as the object category bias and the whole-object constraint (Markman \& Hutchinson, 1984; Markman \& Watchtel, 1988). More specifically, children may assume that a clause tends to express an event, and thus components of a single event are not usually distributed over multiple clauses. Further research is necessary to clarify exactly what notion of clause and event are relevant in such an account.

Alternatively, children may be targeting syntactic structures that are relatively less complex than typical adult ones (i.e., not requiring subordination of verbal elements). Spontaneous speech data from Turkish and Japanese discussed earlier indicates that clause linking with subordinate conjunctions representing temporal simultaneity is acquired late in these languages (i.e., after 3;6). Data from English spontaneous speech reveal similar patterns. Bloom et al. (1980) found that and is the first clausal conjunction acquired in English, used with many different functions. Its first temporal uses, expressing sequencing and simultaneity, appear around 2;4 (note that such constructions would be classified as Loose in our study). No other conjunctions expressing simultaneity were found in their study, which covered the period until age $3 ; 0$. Clark (2003, p. 260) notes that temporal subordinating conjunctions such as while and during, that would be required for Semi-Tight constructions, are not mastered until well after age 5. In contrast, Choi and Bowerman (1991), in an analysis of spontaneous productions, show that children learning English can produce Tight constructions including both Manner and Path elements from as young as 19 months. However, as far as we know, no other study has thoroughly investigated the complexity or frequency of use of syntactic structures that children employ in spontaneous conversations to describe events in which Manner and Path occur 
simultaneously in any of the three languages in our study. This would be a fruitful area for further research.

Since children presumably perceive Manner and Path as occurring simultaneously in our stimuli, expressing the two semantic elements of such a motion event in two verbal clauses could also require a reorganization and reconceptualization of the relations between the two elements. For example, expressing Manner and Path in separate clauses might require children to decompose those elements even though their initial representations are not decomposed. Previous research (Kita \& Özyürek, 2003; Özyürek \& Kita, 1999; Özyürek, Kita, Allen, Furman, $\&$ Brown, 2005) has shown that the gestural representations of adult English speakers for motion events similar to the ones used in the present study are not decomposed, but rather express simultaneously occurring Manner and Path elements in one gesture. However, Japanese and Turkish speakers are more likely to use separate gestures (i.e., one for Manner and one for Path) to depict the same event, suggesting that expressing Manner and Path in separate verbal clauses might require a different linguistic conceptualization. It is possible that this linguistic conceptualization for two-clause construction is difficult for children universally. Further research on children's gestural expression of Manner and Path can shed light on this account.

Finally, given children's apparently strong drive towards Tight syntactic packaging, we are left wondering why Japanese-speaking children produce more targetevent descriptions with Tight packaging than do Turkish-speaking children. We surmise that this is a language-specific effect mitigating the universal tendency. The predominant Tight structure used by Japanese-speaking children involves using a mimetic (sound symbolic word) together with a Path verb, a structure which was used only three times by Japanese-speaking adults in our study. The frequent use of such constructions by children might be due to the abundant use of mimetics in Japanese adult speech along with Manner verbs. For example, 37\% of the all the target-event descriptions with Manner verbs produced by adult Japanese speakers included the use of mimetics (see also Kita, 1997, 2001; for the use of mimetics in Japanese in general). Turkish-speaking children tended to use onomatopoeia to create Tight constructions. However, onomatopoeic expressions are not very frequent in Turkish adult speech, as evidenced by that fact that only one target-event description in our adult Turkish sample used onomatopoeia. Therefore, Turkish-speaking children who want to use onomatopoeia have few models in the input, and must create their own onomatopoeic expressions. This may have limited their ability to produce Tight packaging compared to Japanese-speaking children.

\section{Conclusion}

In sum, we have investigated how children learn to express simultaneously occurring aspects of a spatial event within the linearized and sequential structure of language, and have shown that acquisition of adult-like ways to talk about these 
motion events is not as speedy as previous research has shown. Previous research investigating children's lexical choices to express Manner and Path showed that children follow the patterns preferred in their own language by age 3. Our research reveals that some remnants of universal influence are still visible even at 3 if one looks at the arguably more advanced task of packaging semantic elements together into syntactic units. Children's acquisition is clearly guided by language-specific syntax-semantics mappings, even in the very subtle domain of differential preference for construction types based on the degree of relationship between Manner and Path. However, some preference for compact syntactic constructions such as packaging both elements in one clause rather than two, or perhaps a mapping preference between conceptual and linguistic representations, still has an effect even at age 3. Further study of the developmental trajectory of Manner-Path packaging in older children will illuminate our understanding of this striking juxtaposition of universal and language-specific patterns in language development by revealing when and how the universal tendencies become fully tuned to language-specific patterns.

\section{Acknowledgments}

This research was financially supported by Grant BCS-0002117 from the National Science Foundation to the first three authors, by a Turkish Academy of Sciences (TUBA) Young Scientist Award to Özyürek, and by the Max Planck Institute for Psycholinguistics. Substantial logistical support was provided by Boston University, the Max Planck Institute for Psycholinguistics, Nijmegen, Netherlands, and Koç University, Istanbul, Turkey. Many preschools in Boston, Istanbul, and Tokyo generously allowed us to study the children under their care. Audiences at the Stanford Child Language Research Forum 2002, the Boston University Conference on Language Development 2002, the Canadian Linguistics Association 2004, the University of Connecticut, and the Max Planck Institute for Psycholinguistics offered helpful comments and discussion on previous versions of this paper, as did two anonymous reviewers. We acknowledge with thanks all these contributions to our work.

\section{References}

Aksu-Koç, A., \& Slobin, D. I. (1985). The acquisition of Turkish. In D. I. Slobin (Ed.). The crosslinguistic study of language acquisition (Vol. 1, pp. 839-878). Hillsdale, NJ: Erlbaum.

Allen, S., \& Crago, M. B. (1996). Early passive acquisition in Inuktitut. Journal of Child Language, 23(1), $129-155$.

Berman, R. A., \& Slobin, D. I. (1994). Relating events in narrative: A cross-linguistic developmental study. Hillsdale, NJ: Lawrence Erlbaum Associates.

Bloom, L., Lahey, M., Hood, L., Lifter, K., \& Fiess, K. (1980). Complex sentences: Acquisition of synteactic connectives and the meaning relations they encode. Journal of Child Language, 7, 235-261.

Bowerman, M. (1982). Starting to talk worse: Clues to language acquisition from children's later speech errors. In S. Strauss (Ed.), U-shaped behavioral growth. NewYork: Academic Press. 
Bowerman, M. (1996). Learning how to structure space for language: A crosslinguistic perspective. In P. Bloom, M. Peterson, L. Nadel, \& M. Garrett (Eds.), Language and space. Cambridge, MA: MIT Press.

Bowerman, M., \& Choi, S. (2001). Shaping meanings for language: Universal and language specific in the acquisition of spatial semantic categories. In M. Bowerman \& S. Levinson (Eds.), Language acquisition and conceptual development. Cambridge: Cambridge University Press.

Brugman, H., \& Kita, S. (1995). Impact of digital video technology on transcription: A case of spontaneous gesture transcription. KODIKAS/CODE: Ars Semeiotica An international journal of semiotics, 18, 95-112, [Special issue: D.C. O’Connell, S. Kowal, \& R. Posner (Eds.), Zeichen für Zeit: Zur Notation und Transkription von Bewegungsabläufen].

Choi, S., \& Bowerman, M. (1991). Learning to express motion events in English and Korean: The influence of language-specific lexicalization patterns. Cognition, 41, 83-121.

Clancy, P. M. (1985). The acquisition of Japanese. In D. I. Slobin (Ed.). The crosslinguistic study of language acquisition (Vol. 1, pp. 373-524). Hillsdale, NJ: Erlbaum.

Clancy, P. M., Jacobsen, T., \& Silva, M. (1976). The acquisition of conjunction: A cross-linguistic study. Papers and Reports on Child Language Development, 12, 71-80.

Clark, E. V. (2003). First language acquisition. Cambridge: Cambridge University Press.

Demuth, K. (1990). Subject, topic and Sesotho passive. Journal of Child Language, 17(1), 67-84.

Gentner, D. (1982). Why nouns are learned before verbs: Linguistic relativity versus natural partitioning. In S. A. Kuczaj (Ed.). Language development. Language, thought and culture (Vol. 2). Hillsdale, NJ: Erlbaum.

Gibson, E. J., Owslwy, C. J., \& Johnston, J. (1978). Perception of invariants by five-month-old infants: Differentiation of two types of motion. Developmental Psychology, 14, 407-415.

Goldberg, A. (1997). The relationships between verbs and constructions. In M. Verspoor, K. D. Lee, \& E. Sweetser (Eds.), Lexical and syntactical constructions and the construction of meaning. Amsterdam: John Benjamins.

Hespos, S. J., \& Spelke, E. S. (2004). Precursors to spatial language. Nature, 430, 453-456.

Imai, M., \& Gentner, D. (1993). Linguistic relativity vs. universal ontology: Crosslingusitic studies of the object/substance distinction. Proceedings of the Chicago Linguistic Society.

Johnston, J. R. (1985). Cognitive prerequisties: The evidence from children learning English. In D. Slobin (Ed.). The crosslinguistic study of language acquisition. Theoretical issues (Vol. 2, pp. 1157-1256). Hillsdale, NJ: Erlbaum.

Johnston, J. R., \& Slobin, D. (1979). The development of locative expressions in English, Italian, SerboCroatian and Turkish. Journal of Child Language, 6, 529-545.

Kita, S. (1997). Two-dimensional semantic analysis of Japanese mimetics. Linguistics, 35, $379-415$.

Kita, S. (2001). Semantic schism and interpretive integration in Japanese sentences with a mimetic: A reply to Tsujimura. Linguistics, 39, 419-436.

Kita, S., \& Özyürek, A. (2003). What does cross-linguistic variation in semantic coordination of speech and gesture reveal? Evidence for an interface representation of spatial thinking and speaking. Journal of Memory and Language, 48, 16-32.

Kita, S., Özyürek, A., Allen, S., Brown, A., Furman, R., \& Ishizuka, T. (submitted for publication). Language and event shape gesture: Expressing Manner and Path of motion events in gesture and speech.

Leslie, A. M. (1982). The perception of causality in infants. Perception, 11, 173-186.

Levelt, W. J. M. (1984). Some perceptual limitations on talking about space. In A. J. van Doorn, W. A. vande Grind, \& J. J. Koenderink (Eds.), Limits in perception. Utrecht: VNU Science Press.

Levelt, W. J. M. (1989). Speaking: From intention to articulation. Cambridge, MA: MIT Press.

Markman, E. M., \& Hutchinson, J. E. (1984). Children's sensitivity to constraints on word meaning: Taxonomic versus thematic relations. Cognitive Psychology, 16, 1-27.

Markman, E. M., \& Watchtel, G. F. (1988). Children's use of mutual exclusivity to constrain the meanings of words. Cognitive Psychology, 20, 121-157.

Mayer, M. (1969). Frog, where are you?. New York: Dial Books. 
Needham, A., \& Baillargeon, R. (1993). Intuitions about support in 4.5-month-old infants. Cognition, 47, $121-140$.

Oh, K. -J. (2003). Manner and Path in motion event descriptions in English and Korean. In B. Beachley, A. Brown, \& F. Conlin (Eds.). Proceedings of the 27th Annual Boston University Conference on Language Development. Boston, MA: Cascadilla Press.

Özçalişkan, S., \& Slobin, D. I. (1999). Learning how to search for the frog: Expression of Manner of motion in English, Spanish, and Turkish. In A. Greenhill, H. Littlefield, \& C. Tano (Eds.). Proceedings of the 23rd Annual Boston University Conference on Language Development. Boston, MA, Cascadilla Press.

Özyürek, A., \& Kita, S. (1999). Expressing Manner and Path in English and Turkish: Differences in speech, gesture, and conceptualization. In M. Hahn \& S. C. Stonnes (Eds.), Proceedings of the twentyfirst Annual Meeting of the Cognitive Science Society (pp. 507-512). Hillsdale, NJ: Erlbaum.

Özyürek, A., Kita, S., \& Allen, S. (2001). Tomato Man movies: Stimulus kit designed to elicit manner, path and causal constructions in motion events with regard to speech and gestures. Nijmegen, The Netherlands: Max Planck Institute for Psycholinguistics, Language and Cognition group.

Özyürek, A., Kita, S., Allen, S., Furman, R., \& Brown, A. (2005). How does linguistic framing of events influence co-speech gestures? Insights from crosslinguistic variations and similarities. Gesture, 5, $219-240$.

Özyürek, A., \& Özçalişkan, S. (2000). How do children learn to conflate Manner and Path in their speech and gestures? Differences in English and Turkish. In E. V. Clark (Ed.), Proceedings of the 30th Stanford Child Language Research Forum. Stanford, CA: CSLI.

Papafragou, A., Massey, C., \& Gleitman, L. (2002). Shake, rattle, 'n' roll: The representation of motion in language and cognition. Cognition, 84, 189-219.

Piaget, J., \& Inhelder, B. (1956). The child's conception of space. London: Routledge \& Kegan Paul.

Pruden, S., Hirsh-Pasek, K., Maguire, M., \& Meyer, M. (2004). Foundations of verb learning: Infants categoriezez path and manner in motion events. In A. Brugos, L. Micciulla \& C. E. Smith (Eds.). Proceedings of the 28th Annual Boston University Conference on Language Development (pp. 461-472). Boston, MA: Cascadilla Press.

Pulverman, R., Sootsman, J., Golinkoff, R. M., \& Hirsh-Pasek, K. (2003). The role of lexical knowledge in nonlinguistic event processing: English-speaking infants' attention to Manner and Path. In B. J. Beachley, A. Brown \& F. Conlin (Eds.), Proceedings of the 27th Annual Boston University Conference on Language Development (pp. 662-673). Boston, MA: Cascadilla Press.

Pulverman, R., Golinkoff, R. M. (2004). Seven-month-olds' attention to potential verb referents in nonlinguistic events. In A. Brugos, L. Micciulla \& C. E. Smith (Eds.), Proceedings of the 28th Annual Boston University Conference on Language Development (pp. 473-481). Boston, MA: Cascadilla Press.

Pye, C., \& Quixtan Poz, P. (1988). Precocious passives (and antipassives) in Quiche Mayan. Papers and Reports on Child Language Development, 27, 71-80.

Slobin, D. I. (1973). Cognitive prerequisites for the development of grammar. In C. A. Ferguson \& D. I. Slobin (Eds.), Studies of child language development (pp. 175-208). New York: Holt, Rinehart \& Winston.

Slobin, D. I. (1982). Universal and particular in the acquisition of language. In E. Wanner \& L. R. Gleitman (Eds.), Language acquisition: The state of the art. Cambridge: Cambridge University Press.

Slobin, D. I. (1985). Crosslinguistic evidence for the language-making capacity. In D. I. Slobin (Ed.). The crosslinguistic study of language acquisition, Theoretical issues (Vol. 2, pp. 1157-1256). Hillsdale, NJ: Erlbaum.

Slobin, D. I. (1987). Thinking for speaking. In Proceedings of the 13th Annual Meeting of the Berkeley Linguistics Society (pp. 435-445). Berkeley, CA: Berkeley Linguistics Society.

Slobin, D. I. (1996). Two ways to travel: Verbs of motion in English and Spanish. In M. Shibatani \& S. A. Thompson (Eds.), Grammatical constructions (pp. 195-220). Oxford: Clarendon Press.

Slobin, D. I. (2003). Language and thought on-line: Cognitive consequences of linguistic relativity. In D. Gentner \& S. Goldin-Meadow (Eds.), Language in mind: Advances in the study of language and thought (pp. 157-193). Cambridge, MA: MIT Press. 
Spelke, E. S., Breilenger, K., Macomber, J., \& Jacobson, K. (1985). Origins of knowledge. Psychological Review, 99, 605-632.

Talmy, L. (1985). Lexicalization patterns: Semantic structure in lexical forms. Vol. III: Grammatical categories and the lexicon. In T. Shopen (Ed.), Language typology and syntactic description (pp. 57-149). Cambridge: Cambridge University Press.

Tardif, T. (1996). Nouns are not always learned before verbs, but why? Evidence for a verb bias in Mandarin speakers' early vocabularies. Developmental Psychology, 32, 492-504. 